\title{
The role of adjunctive antibiotics in the treatment of skin and soft tissue abscesses: a systematic review and meta-analysis
}

\author{
Jahan Fahimi, MD, $\mathrm{MPH}^{*{ }^{\dagger \neq}}$; Amandeep Singh, MD*; Bradley W. Frazee, MD*
}

\section{ABSTRACT}

Objective: To perform a review and meta-analysis on the effect of antibiotics on treatment of skin and soft tissue abscesses (SSTAs) after incision and drainage.

Methods: We searched MEDLINE, EMBASE, Web of Knowledge, and Google Scholar databases to identify randomized controlled trials (RCTs) and observational studies. For RCTs, we included studies comparing any antibiotic (treatment) to placebo (control). For observational studies, treatment was the use of appropriate antibiotics effective against bacterial isolate, and control was the use of inappropriate (ineffective) or no antibiotics. Outcome was treatment success during follow-up. Two investigators reviewed records, assessed quality (according to Cochrane and NewcastleOttawa tools), and extracted treatment success rates. Primary analysis was the effect of treatment among RCTs. Secondary analyses included the effect of treatment in 1) observational studies of confirmed methicillin-resistant Staphylococcus aureus (MRSA) infection (MRSA-only) and 2) all studies after 1998 (MRSA-era). We used random effects modelling, except when no heterogeneity was present when we used fixed effects.

Results: We screened 1,968 records. Twelve were included (five RCTs, seven observational studies), representing 1,969 subjects. Seven enrolled from emergency departments, two from surgical clinics, and three from ambulatory clinics. Three enrolled children only. Pooled relative risk (RR) of treatment success among RCTs was 1.03 (95\% confidence interval $[\mathrm{Cl}] 0.97-1.08)$. Pooled RR in the secondary analyses was $1.05(95 \% \mathrm{Cl} 0.96-1.15)$ in MRSAonly and 0.99 (95\% Cl $0.98-1.01)$ in MRSA-era.

Conclusion: Despite limitations in pooling available data, there is no clear evidence to support antibiotic use in treating uncomplicated SSTAs.

\section{RÉSUMÉ}

Objectif: L'étude visait à réaliser une revue systématique et une méta-analyse des études portant sur l'effet des antibiotiques dans le traitement des abcès de la peau et des tissus mous (APTM) après incision et évacuation.

Méthode: Une recherche a été entreprise dans les bases de données MEDLINE, EMBASE, Web of Knowledge et Google
Scholar afin de relever des essais comparatifs à répartition aléatoire (ECRA) et des études d'observation. En ce qui concerne les ECRA, les études dans lesquelles il y avait une comparaison entre un traitement antibiotique quelconque (groupe expérimental) et un traitement placébo (groupe témoin) étaient retenues. En ce qui concerne les études d'observation, les traitements consistaient en I'utilisation appropriée d'antibiotiques efficaces contre des isolats de bactéries; et les interventions témoins, en I'utilisation non appropriée (inefficace) ou la non-utilisation d'antibiotiques. Le résultat recherché était la réussite du traitement pendant le suivi. Deux chercheurs ont passé en revue les documents relevés, évalué la qualité (selon les outils Cochrane et Newcastle-Ottawa) et dégagé les taux de réussite des traitements. L'analyse principale avait pour objet l'effet du traitement dans les ECRA; les analyses secondaires portaient sur l'effet du traitement dans: 1) les études d'observation de cas d'infection avérée à Staphylococcus aureus résistant à la méthicilline (SARM seul); 2) toutes les études menées après 1998 (époque des infections à SARM). Les auteurs ont eu recours au modèle à effets aléatoires, sauf dans les cas où le modèle à effets fixes ne décelait aucune hétérogénéité.

Résultats: Ont été relevés 1968 documents; 12 recherches (5 ECRA, 7 études d'observation) totalisant 1969 sujets ont été retenues. Dans 7 recherches, les patients provenaient de services d'urgence; dans 2 recherches, de centres ou de services de chirurgie; et dans 3 recherches, de services de soins ambulatoires. Trois recherches ne portaient que sur les enfants. Le risque relatif ( $R R$ ) global de la réussite du traitement dans les ECRA était de 1,03 ( $\mathrm{Cl}$ à $95 \%$ : 0,97-1,08), et celui dans les analyses secondaires, de 1,05 $(\mathrm{Cl}$ à $95 \%$ : $0,96-1,15)$ dans les cas de SARM seul, et de $0,99(\mathrm{Cl}$ à $95 \%$ : $0,98-1,01)$ dans les cas traités durant l'époque des infections à SARM.

Conclusion: Malgré les faiblesses de la réunion des données existantes, rien n'étaye l'emploi des antibiotiques dans le traitement des APTM sans complications.

Keywords: abscess, antibacterial agents, methicillin-resistant Staphylococcus aureus

From the *Department of Emergency Medicine, Alameda Health System, Highland Hospital, Oakland, CA; †Department of Emergency Medicine, University of California, San Francisco, CA; and ¥Division of Epidemiology, Berkeley School of Public Health, University of California, Berkeley, CA

Correspondence to: Dr. Jahan Fahimi, Department of Emergency Medicine, Alameda Health System, Highland Hospital, 1411 East 31 st Street, Oakland, CA 94602; jahan.fahimi@ucsf.edu 


\section{INTRODUCTION}

Skin and soft tissue abscesses (SSTAs) comprise a number of pathologic entities with a spectrum of severity. Cutaneous abscesses involve the dermis and hypodermis and may be polymicrobial (containing bacteria found on nearby skin and mucosa) or due to Staphylococcus aureus (S. aureus) alone. Furuncles, the most common type of SSTA, develop spontaneously within hair follicles and are usually caused by $S$. aureus. ${ }^{1}$ Deeper soft tissue abscesses, including intramuscular abscesses, may be caused by injection drug use. The amount of cellulitis associated with SSTAs varies, but systemic toxicity is uncommon.

The late 1990s and early 2000s saw the worldwide emergence of community-associated methicillin-resistant S. aureus (CA-MRSA). While CA-MRSA can cause severe invasive infections, it predominantly causes SSTAs in young, otherwise healthy individuals. ${ }^{2,3}$ Between 1997 and 2005, outpatient visits in the United States for skin and soft tissue infections rose by $50 \%$ and more than doubled at emergency departments (EDs). ${ }^{4}$ In 2008, CA-MRSA accounted for $59 \%$ of all culturable skin and soft tissue infections in the U.S. EDs, $85 \%$ of which were abscesses. ${ }^{5}$

Current guidelines from the Infectious Disease Society of America (IDSA) emphasize that the primary treatment for SSTAs, including those due to CA-MRSA, is incision and drainage. ${ }^{6}$ According to such guidelines, adjunctive antibiotics should be reserved for complicated abscesses. Among features indicating complicated infection, the presence of associated cellulitis, in particular, provides a reason to prescribe antibiotics in many cases, because some induration and erythema surround most SSTAs.

Evidence on the potential benefit of adjunctive antibiotics, in addition to incision and drainage, in the treatment of uncomplicated SSTAs consists of several small, randomized controlled trials (RCTs) and data from observational studies. ${ }^{2,3,7-8}$ Although most RCTs demonstrate no benefit, a few show a trend toward benefit, ${ }^{7,11}$ and some authors have argued that these studies were underpowered to show a benefit that likely exists. ${ }^{9}$ A 2007 systematic review and 2013 meta-analysis found no benefit from adjunctive antibiotics. ${ }^{10,11}$ Both studies had important limitations. The 2007 systematic review did not include data from two recent RCTs and four observational studies. Many trials included in the review were conducted before the emergence of CA-MRSA, and it is possible that SSTAs due to CA-MRSA are unique and benefit more from antibiotics.
The meta-analysis was limited to only RCTs and missed one important RCT and all observational study data. The report also failed to address the possibility that SSTAs caused by CA-MRSA represent a distinct entity. Although many of the observational studies of SSTA treatment have been conducted since the emergence of CA-MRSA, data from these studies have yet to be appraised in combination with RCTs.

Lacking robust, contemporary evidence to guide clinical practice, and possibly concerns over the potential for CA-MRSA to cause more severe infections, it seems that clinicians continue to err on the side of prescribing antibiotics. Presented with a hypothetical case of an uncomplicated SSTA, a non-random sample of polled clinicians worldwide would prescribe adjunctive antibiotics. ${ }^{12}$ In the United States, emergency physicians prescribe antibiotics for roughly $75 \%$ of abscess/cellulitis cases, increasingly choosing an antibiotic active against MRSA. ${ }^{13}$ As the prevalence of these infections has increased, so has the number of antibiotic prescriptions.

Given continued uncertainty about the role of antibiotics in the treatment of SSTAs, we saw a need for a systematic appraisal of the relevant literature, including observational studies. Our objective was to assess the effect of adjunctive antibiotics, in addition to incision and drainage on treatment success in uncomplicated SSTAs.

\section{METHODS}

\section{Study design}

We performed a systematic review and meta-analysis of the effect of antibiotics on the treatment of uncomplicated SSTAs. Our study conforms to PRISMA Statement guidelines for systematic reviews ${ }^{14}$ and MOOSE guidelines for observational studies. ${ }^{15}$ Our study protocol is available upon request.

\section{Search strategy and selection criteria}

In conjunction with a medical librarian, we performed a comprehensive literature search of the following databases: MEDLINE (1950 to December 2013), EMBASE (1974 to December 2013), Web of Knowledge (1970 to December 2013), and Google Scholar (no date restriction). Our search strategy and terms can be found in Appendix 1. All languages were included. We included only studies of primary data. 
We searched ClinicalTrials.gov to identify unpublished trials and contacted investigators in an attempt to obtain any pilot, preliminary, or otherwise unpublished data. We reviewed reference lists of studies, review articles, and editorials, and consulted with topic experts, to identify additional studies not retrieved by the search.

We included RCTs and observational cohort studies from ED or ambulatory care settings, with adult and pediatric subjects. We included RCTs that satisfied the following criteria: 1) patients with SSTAs who underwent incision and drainage, 2) treatment group that included any antibiotics, 3) control group that included placebo, and 4) treatment failure or success that was ascertained on follow-up. For observational studies, the criteria were 1) patients with SSTAs who underwent incision and drainage, 2) treatment group that included appropriate antibiotics (defined in the section on interventions and outcomes), 3) control group that included no antibiotics or inappropriate antibiotics (defined in the section on interventions and outcomes), and 4) treatment failure or success that was ascertained on follow-up. We excluded studies where the abscess cavity was sutured closed. Our rationale was that, because most studies retrieved by our search involved incision and drainage alone (as recommended by the IDSA $^{6}$ ), by including studies of primary suture closure, we would introduce another significant source of heterogeneity while adding relatively few subjects to the analysis. We also excluded studies of postsurgical wounds.

\section{Screening and data abstraction}

Two authors (Fahimi and Singh) reviewed abstracts retrieved by the initial search strategy with respect to the inclusion and exclusion criteria. Full articles were reviewed when one or both authors deemed the abstract appropriate. The authors independently assessed suitability of studies for inclusion in the meta-analysis and reached complete agreement. When published data were incomplete or did not provide sufficient information for pooling, we attempted to contact the authors for additional data that would allow inclusion. Additional data from author correspondence were included after all three authors agreed. For each study, sample sizes, treatment allocation, and treatment success were extracted by two authors (Fahimi and Singh) and determined by consensus.

\section{Interventions and outcomes}

For RCTs, we defined our intervention group as patients who received an antibiotic and our control group as patients who received either no antibiotic or placebo. For observational studies of patients with culture-positive abscesses, appropriate therapy was defined as an antibiotic to which the bacterial isolate was susceptible in vitro, and inappropriate as one to which the isolate was resistant. We adhered to an intention-to-treat approach and report medication adherence for each arm when available from the data. Our primary outcome was treatment success, that is, lack of treatment failure. Treatment failure was defined as persistence of the primary infection at the end of the treatment period or need for an additional intervention or procedure. Although this outcome definition is broad, our inability to differentiate types of treatment failure stems from nonuniform outcome definitions and limited data presented in the primary studies.

For this analysis, we assumed that the following variables would not significantly affect pooled results: study setting, identification and selection of patients with an abscess requiring drainage, drainage technique, duration of antibiotic administration, and postprocedural care.

\section{Quality scoring}

Two authors (Fahimi and Singh) assessed the quality of included studies. RCTs were appraised according to guidelines published by the Cochrane Collaboration. ${ }^{16}$ For observational studies, we applied the NewcastleOttawa Scale quality assessment tool. ${ }^{17}$ There was complete agreement on quality assessment.

\section{Meta-analysis}

We calculated relative risks (RR) of treatment success with $95 \%$ confidence intervals (CI) for each study. Our primary analysis pooled all RCTs comparing antibiotics to placebo. We performed two secondary analyses: 1) effect of appropriate antibiotics (defined as those to which the isolate proved susceptible in vitro) compared to inappropriate antibiotics (to which the isolate was not susceptible in vitro) or no antibiotics, in observational studies of patients with confirmed MRSA infection (termed culture-proven MRSA-only analysis); and 
2) effect of antibiotics compared to placebo in RCTs, or appropriate antibiotics compared to inappropriate or no antibiotics in observational studies, restricted to studies in which all patients were enrolled after 1995 (termed MRSA-era analysis). ${ }^{18}$ This analysis assumed nonuniform prevalence of MRSA across study populations or geographic areas. A summary of the analyses, including study types and comparison groups, can be seen in Appendix 2.

The MRSA-era analysis was an attempt to include a population of subjects and SSTAs with MRSA prevalence similar to that encountered today. Combining data from both RCTs and cohort studies to meta-analyse the effect of an intervention is well supported and may provide significant advantages over pooling results from RCTs only. ${ }^{19,20}$ Our intervention categories, appropriate and inappropriate antibiotics, based on in vitro susceptibility data in observational trials, correspond with, but admittedly are not equivalent to, antibiotic therapy and placebo in RCTs. Grouping together interventions that were not precisely equivalent was necessary, however, in order to allow pooling of data between observational studies and between observational studies and RCTs.

We assessed for heterogeneity by the $\chi^{2}$ test statistic. From this, we calculated the $I^{2}$ statistic $\left(I^{2}=100 \% \mathrm{x}\right.$ $\left.\left[\chi^{2}-\mathrm{df}\right] / \chi^{2}\right)$, which is the percentage of total variation across studies due to heterogeneity rather than chance. Traditionally, cut-offs of $25 \%, 50 \%$, and $75 \%$ correspond respectively to low, moderate, and high levels of heterogeneity, ${ }^{21}$ though some authors consider high heterogeneity to be at $I^{2}$ levels greater than $50 \% .^{22}$ Negative $I^{2}$ values were put equal to zero, suggesting no observed heterogeneity. If no heterogeneity was present, we used a fixed effects model as described by Greenland ${ }^{23}$ to calculate the pooled RR. When studies were found to be heterogeneous $\left(\chi^{2}>\mathrm{df}\right)$, we report results from a random effects model and, secondarily, from a fixed effects model with the $95 \%$ CI recalculated using the adjustment described by Shore et al., where between-study heterogeneity is incorporated into calculations of variance. ${ }^{24,25}$ Publication bias was evaluated through visual inspection of funnel plots, as well as through both Egger's ${ }^{26}$ and Begg's ${ }^{27}$ tests for smallstudy effects. We report the kappa statistic for interreviewer agreement for inclusion of studies. Statistical analysis was done using Microsoft Excel (Microsoft, Redmond, WA) and Stata 11.1 (StataCorp, College Station, TX).

\section{RESULTS}

We screened 1,968 records retrieved in the computerized search and 10 studies identified by reviewing reference sections and through discussion with topic experts. We contacted the investigators of four ongoing trials but were unable to obtain any preliminary, pilot, or otherwise unpublished data. Inter-reviewer agreement for inclusion of records (title and abstract) was excellent (kappa $=0.88)$.

We reviewed the full text of 19 studies (7 RCTs and 12 observational studies). Seven studies were excluded after review. There was complete agreement between reviewers on which of these studies fulfilled inclusion criteria (kappa $=1.0)$. Details of the excluded studies are highlighted in Appendix 3. In three observational studies, the data could not be directly pooled. We contacted the authors who provided additional information allowing us to include the studies in the metaanalysis. ${ }^{3,16,17}$ We ultimately included 12 studies (5 trials and 7 observational studies) in our analyses with a total of 1,969 subjects. Our study selection and inclusion process are outlined in Figure 1.

\section{Characteristics of studies}

The primary meta-analysis included five RCTs. One trial, done in 1977, lacked clear description of the methodology ${ }^{7}$ (Table 1). The remaining four trials used proper randomization and blinding techniques and were free of selective reporting bias. The majority suffered from incomplete outcome data due to high lost to follow-up rates. ${ }^{8-11}$ Additional sources of bias were inclusion of patients on antibiotics prior to enrollment, ${ }^{7}$ and use of beta-lactam antibiotics despite a high rate of CA-MRSA in the study population. ${ }^{9}$ Four of the RCTs were placebo-controlled. ${ }^{8-11}$ Treatment failure was defined as the need for repeat incision and drainage and/or need for antibiotics, except in one trial where it was defined as persistent infection. ${ }^{8}$ Adherence with therapy was not assessed in three trials. ${ }^{7,9,11}$ In the remaining two trials, adherence with therapy was generally poor. ${ }^{8,10}$ We noted a wide range in reported rates of treatment failure between trials (median $4.1 \%$, range $0 \%-17 \%$ in the antibiotic group and median $5.3 \%$, range $3.7 \%-26.5 \%$ in the no antibiotic group). Details of the included RCTs are presented in Table 2.

The seven observational studies included five cohort studies-one prospective ${ }^{12}$ and four 


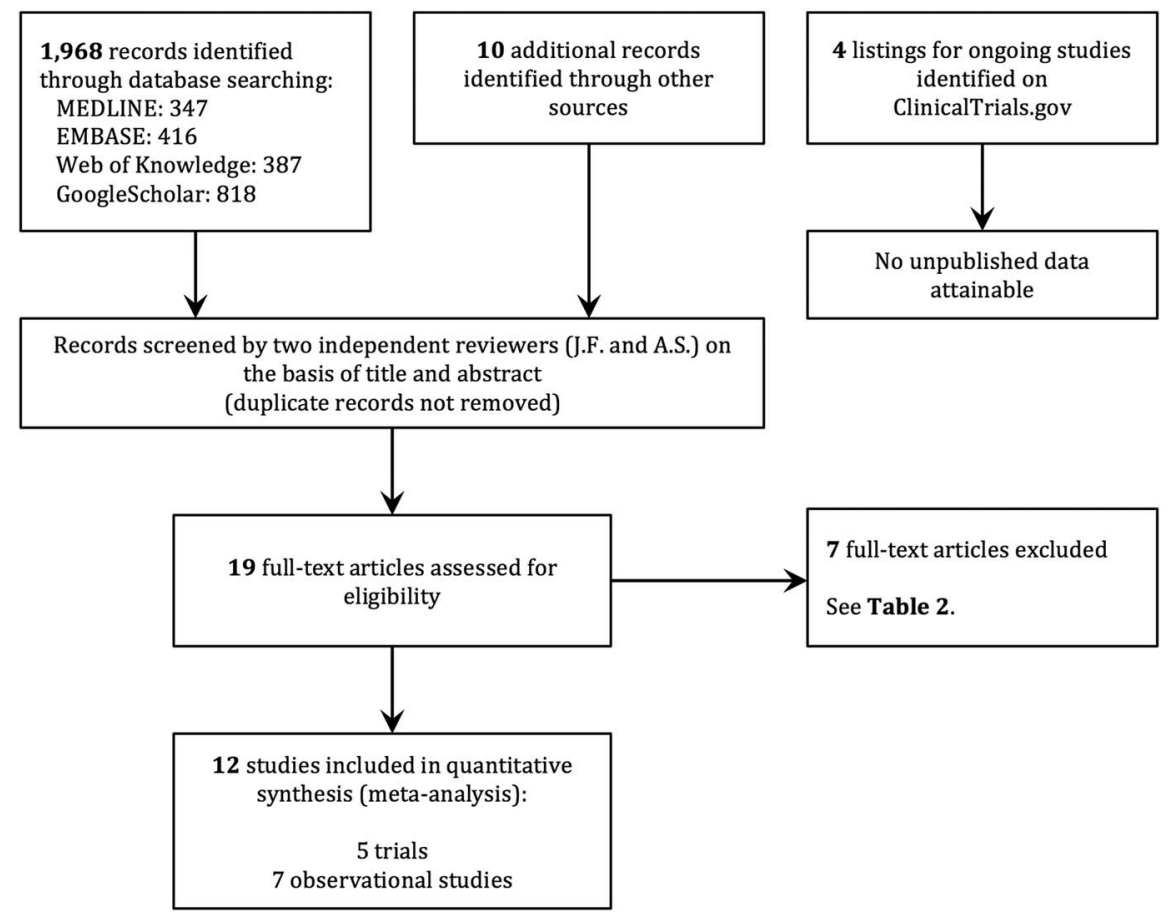

Figure 1. Outline of study selection and inclusion.

\begin{tabular}{|c|c|c|c|c|c|c|}
\hline & $\begin{array}{c}\text { Adequate sequence } \\
\text { generation }\end{array}$ & $\begin{array}{c}\text { Allocation } \\
\text { concealment }\end{array}$ & Blinding & $\begin{array}{l}\text { Incomplete outcome } \\
\text { data assessed }\end{array}$ & $\begin{array}{l}\text { Free of selective } \\
\text { reporting }\end{array}$ & $\begin{array}{c}\text { Free of } \\
\text { other bias }\end{array}$ \\
\hline Macfie 1977 & $?$ & $?$ & - & $?$ & + & - \\
\hline Llera 1985 & + & + & + & - & + & + \\
\hline Rajendran 2007 & + & + & + & + & + & - \\
\hline Duong 2010 & + & + & + & - & + & + \\
\hline Schmitz 2010 & + & + & + & - & + & + \\
\hline
\end{tabular}

retrospective ${ }^{13-15,17}$ - that primarily assessed antibiotic effect on treatment success. Data from subgroups of two studies that did not primarily examine antibiotic use were also included. One of these studies was a trial of abscess drainage techniques, ${ }^{16}$ and the other study was a large cohort study of skin and soft tissue infections. ${ }^{3}$ The use of appropriate antibiotics was compared to inappropriate antibiotics in four studies, ${ }^{13-15,17}$ to no antibiotics in two studies, ${ }^{12,16}$ and to inappropriate or no antibiotics in one. ${ }^{3}$ Details of these studies are shown in Table 3 , and a quality assessment summary is shown in Table 4.

Of the 12 included studies, only 6 reported loss to follow-up. ${ }^{8-11,13,14}$ Among those who did report, not all classified from which arm that the loss came.
Otherwise, no evidence for differential loss to follow-up was found. All but one of the studies reported no financial disclosures. In that case, multiple authors were on advisory boards of pharmaceutical companies. ${ }^{3}$

\section{Results of primary analysis}

None of the five RCTs in the primary meta-analysis showed a significant benefit to antibiotic treatment. The pooled RR of treatment success with antibiotics using a random effects model was 1.03 (95\% CI $0.97-1.08$ ) (Figure 2). Tests of heterogeneity resulted in $\chi^{2}=5.81 \quad(p<0.21)$, with an $I^{2}=31.2 \%$, corresponding to moderate heterogeneity. Differences among studies that contribute to heterogeneity include 


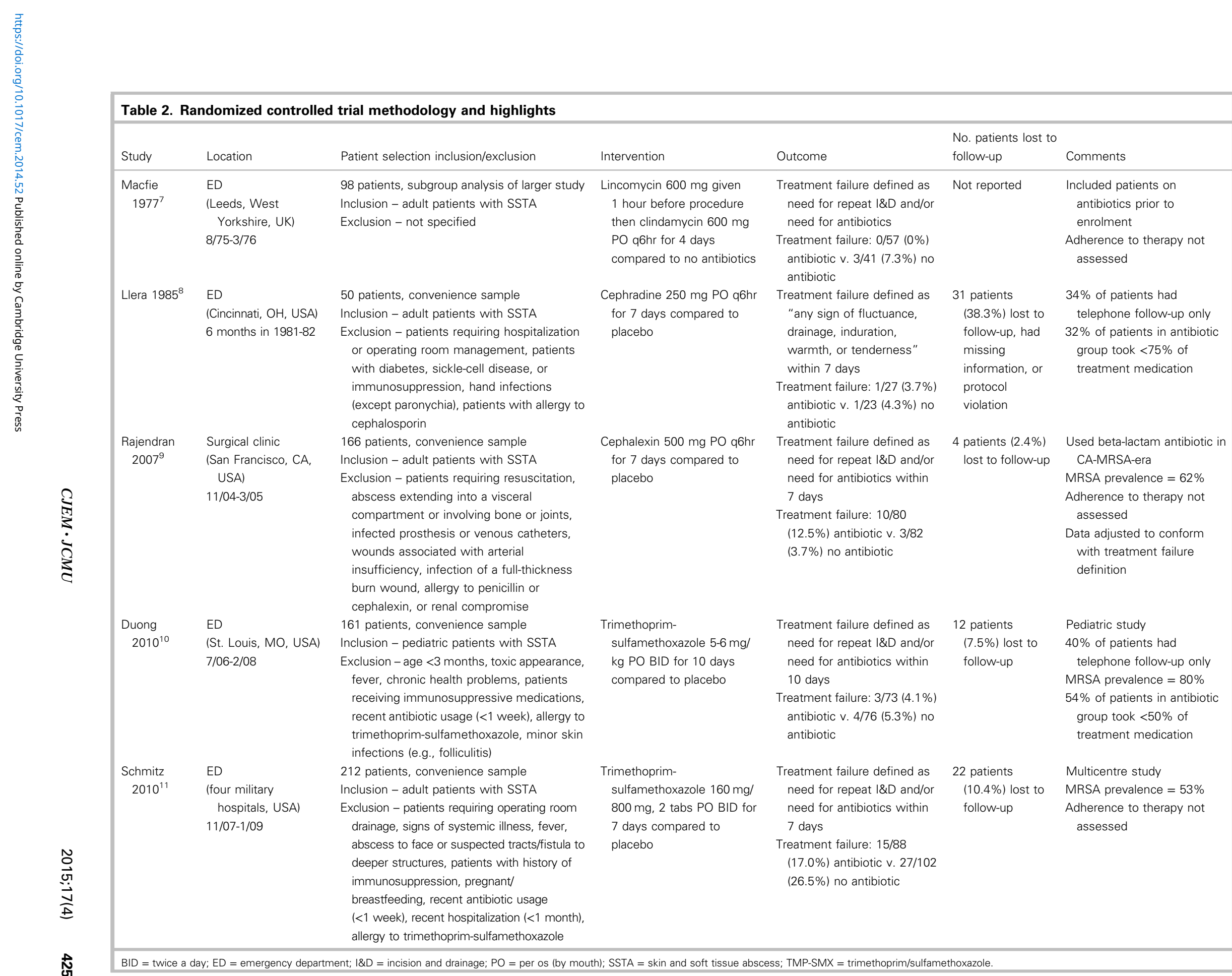




\begin{tabular}{|c|c|c|c|c|c|c|}
\hline $\begin{array}{l}\text { Study } \\
\text { (study \#) }\end{array}$ & Location & $\begin{array}{l}\text { Patient selection inclusion/ } \\
\text { exclusion }\end{array}$ & Intervention* & Outcome & $\begin{array}{l}\text { No. patients lost to } \\
\text { follow-up }\end{array}$ & Comments \\
\hline $\begin{array}{l}\text { Meislin } \\
1977^{12}\end{array}$ & $\begin{array}{l}\text { ED } \\
\text { (Chicago, IL, USA) }\end{array}$ & $\begin{array}{l}135 \text { abscesses in } 133 \text { patients, } \\
\text { convenience sample } \\
\text { Inclusion - all patients with SSTA } \\
\text { Exclusion - hospital admission, } \\
\text { systemic infection, } \\
\text { immunosuppressed, serious } \\
\text { underlying illness, abscess }<1 \mathrm{~cm}\end{array}$ & $\begin{array}{l}\text { Any antibiotics compared } \\
\text { to no antibiotics }\end{array}$ & $\begin{array}{l}\text { Treatment failure defined as need for repeat } \\
\text { I\&D and/or need for antibiotics } \\
\text { Treatment failure: } 0 / 35(0 \%) \text { antibiotic vs. 0/ } \\
100(0 \%) \text { no antibiotic }\end{array}$ & Not Reported & $\begin{array}{l}\text { Adherence to therapy not } \\
\text { assessed }\end{array}$ \\
\hline Lee $2004^{13}$ & $\begin{array}{l}\text { ED and Pediatric } \\
\text { Acute Care Clinic } \\
\text { (Dallas, TX, USA) } \\
\text { 5/02-2/03 }\end{array}$ & $\begin{array}{l}67 \text { patients } \\
\text { Inclusion - pediatric patients with } \\
\text { SSTA that cultured positive for } \\
\text { MRSA } \\
\text { Exclusion - hospital admission }\end{array}$ & $\begin{array}{l}\text { Appropriate antibiotics } \\
\text { compared to } \\
\text { inappropriate antibiotics }\end{array}$ & $\begin{array}{l}\text { Treatment failure defined as "tenderness, } \\
\text { erythema, fever, wound discharge, or } \\
\text { increased size on infection" at } 7 \text { days } \\
\text { Treatment failure: } 0 / 24(0 \%) \text { appropriate vs. } 5 / \\
\quad 36(13.9 \%) \text { inappropriate antibiotic }\end{array}$ & $\begin{array}{l}7 \text { patients (10.4\%) } \\
\text { lost to follow-up }\end{array}$ & $\begin{array}{l}\text { MRSA-only cohort } \\
\text { Pediatric study } \\
32 \% \text { of patients had } \\
\text { intravenous antibiotic } \\
\text { during initial evaluation } \\
\text { Adherence to therapy not } \\
\text { assessed }\end{array}$ \\
\hline $\begin{array}{l}\text { Moran } \\
2006^{3}\end{array}$ & $\begin{array}{l}\text { ED } \\
\text { (EMERGEncy ID Net) } \\
8 / 04\end{array}$ & $\begin{array}{l}178 \text { patients, subgroup analysis } \\
\text { of larger study } \\
\text { Inclusion - adult patients with } \\
\text { SSTA } \\
\text { Exclusion - not fully specified }\end{array}$ & $\begin{array}{l}\text { Appropriate antibiotics } \\
\text { compared to } \\
\text { inappropriate antibiotics } \\
\text { or no antibiotics }\end{array}$ & $\begin{array}{l}\text { Treatment failure defined as infection that } \\
\text { had not "resolved or improved" at } \\
15-21 \text { days } \\
\text { Treatment failure: } 1 / 47(2.1 \%) \text { appropriate vs. } \\
1 / 52(1.9 \%) \text { inappropriate vs. } 1 / 37(2.7 \%) \\
\text { no antibiotic }\end{array}$ & $\begin{array}{l}\text { NA - author only } \\
\text { provided } \\
\text { information } \\
\text { regarding patients } \\
\text { with full follow-up } \\
\text { information }\end{array}$ & $\begin{array}{l}\text { Data obtained by contacting } \\
\text { the author } \\
\text { MRSA prevalence }=59 \% \\
\text { Follow-up by telephone only } \\
\text { Adherence to therapy not } \\
\text { assessed }\end{array}$ \\
\hline $\begin{array}{l}\text { Paydar } \\
2006^{14}\end{array}$ & $\begin{array}{l}\text { Surgical clinic } \\
\text { (San Francisco, CA, } \\
\text { USA) } \\
\text { 7/00-8/01 }\end{array}$ & $\begin{array}{l}450 \text { abscesses in } 376 \text { patients } \\
\text { MRSA subgroup included } 284 \\
\text { abscesses } \\
\text { Inclusion - adult patients with } \\
\text { SSTA that cultured positive } \\
\text { Exclusion - not specified }\end{array}$ & $\begin{array}{l}\text { Appropriate antibiotics } \\
\text { compared to } \\
\text { inappropriate antibiotics }\end{array}$ & $\begin{array}{l}\text { Treatment failure defined as "persistence of } \\
\text { infection ... requiring further major } \\
\text { treatment (e.g. osteomyelitis, amputation, } \\
\text { patient death, severe soft tissue infection } \\
\text { requiring operative debridement)" at } 14+ \\
\text { days (mean } 2 \text { months) } \\
\text { Treatment failure: } 2 / 166(1.2 \%) \text { appropriate } \\
\text { vs. } 1 / 242(0.4 \%) \text { inappropriate antibiotic } \\
\text { MRSA subgroup: } \\
\text { Treatment failure: } 1 / 25(4 \%) \text { appropriate vs. } \\
\text { 1/259 }(0.4 \%) \text { inappropriate antibiotic }\end{array}$ & $\begin{array}{l}33 \text { patients (8.8\%) } \\
\text { lost to follow-up }\end{array}$ & $\begin{array}{l}\text { Retrospective study } \\
\text { MRSA prevalence }=64 \% \\
\text { Adherence to therapy not } \\
\text { assessed }\end{array}$ \\
\hline $\begin{array}{l}\text { Ruhe } \\
2007^{17}\end{array}$ & $\begin{array}{l}\text { ED and ambulatory } \\
\text { clinic } \\
\text { (Little Rock, AR, USA) } \\
\text { 2/03-2/06 }\end{array}$ & $\begin{array}{l}415 \text { patients } \\
\text { Inclusion - SSTA that cultured } \\
\text { positive for MRSA } \\
\text { Exclusion - folliculitis, impetigo, } \\
\text { or, complicated infection } \\
\text { (nonhealing skin ulcer, diabetic } \\
\text { foot infection, post-surgical } \\
\text { wound infection, or involving } \\
\text { deep tissue structures, } \\
\text { including bone, fascia, or } \\
\text { tendon sheaths) }\end{array}$ & $\begin{array}{l}\text { Appropriate antibiotics } \\
\text { compared to } \\
\text { inappropriate antibiotics }\end{array}$ & $\begin{array}{l}\text { Treatment failure defined as need for repeat } \\
\text { I\&D, hospital admission, occurrence of new } \\
\text { infection, or microbiological failure at } 2+ \\
\text { days } \\
\text { Treatment failure: } 14 / 235(6.0 \%) \text { appropriate } \\
\text { v. } 24 / 180(13.3 \%) \text { inappropriate antibiotic }\end{array}$ & Not reported & $\begin{array}{l}\text { MRSA-only cohort } \\
\text { Retrospective study } \\
\text { Data obtained by contacting } \\
\text { the author } \\
\text { Data excludes } 116 \text { patients } \\
\text { with cellulitis } \\
\text { Adherence to therapy not } \\
\text { assessed }\end{array}$ \\
\hline
\end{tabular}




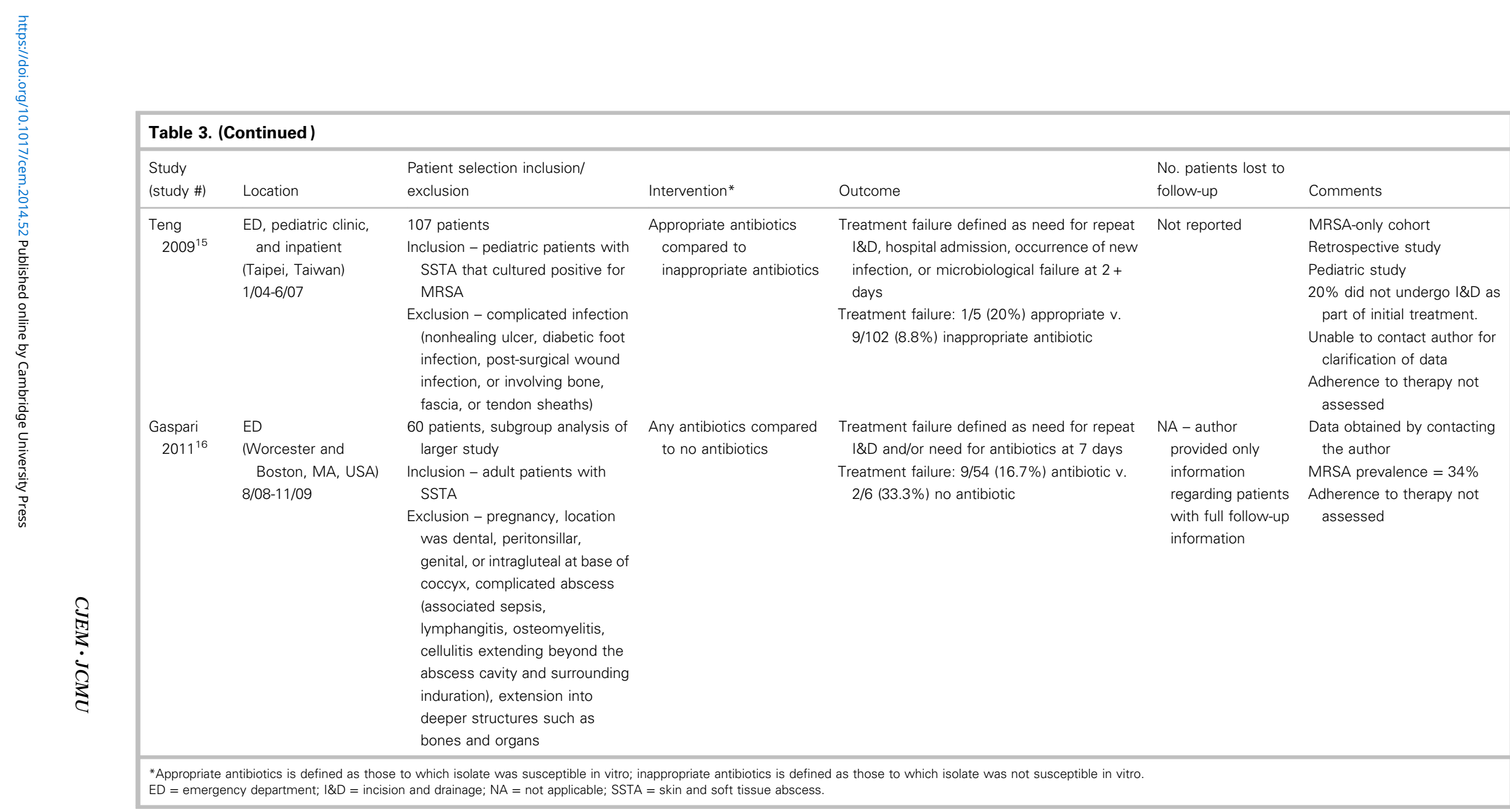




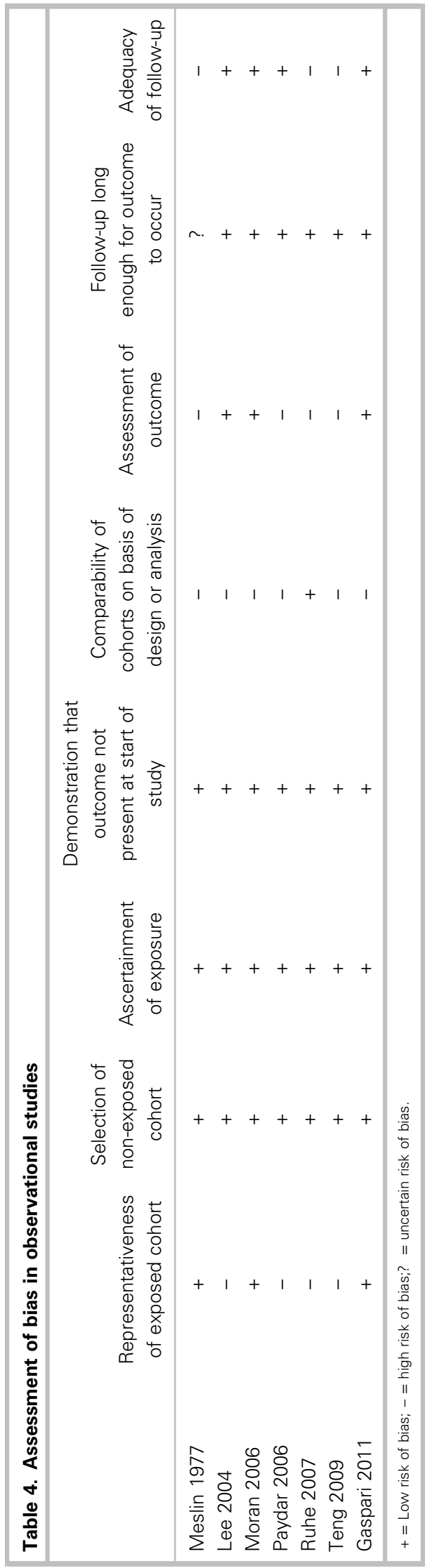

the year that they were conducted (before or after the emergence of CA-MRSA), study setting (e.g., pediatric ED v. surgical clinic), types of antibiotics used, exact definition of treatment failure, method of follow-up (direct wound inspection v. phone follow-up), and assessment of antibiotic adherence. A funnel plot, as well as both the Egger's and Begg's tests, showed no evidence of publication bias.

\section{Secondary analyses}

In the four studies limited to culture-proven MRSAonly infections, the pooled RR of treatment success with appropriate antibiotics (defined previously), as compared to inappropriate or no antibiotics, was 1.05 (95\% CI $0.96-1.15)$. When the results of the three randomized trials and three observational studies conducted in the MRSA-era were combined (using the fixed effects model because there was no observable heterogeneity), the pooled RR of treatment success with antibiotics/appropriate antibiotics was 0.99 (95\% CI $0.98-1.01)$. This result was unchanged after excluding the single RCT that used an antibiotic known to be inactive against $\mathrm{MRSA}^{9}$ (data are not shown). The prevalence of MRSA in the MRSA-era studies ranged from $34 \%$ to $80 \%$. A summary of these results, including measures of heterogeneity, is presented in Table 5 and Figure 3. Funnel plots for all analyses and all 12 included studies can be found in Appendix 4. One study $^{12}$ was not ultimately included in any of the three quantitative meta-analyses because it was an observational study and predated the emergence of MRSA. In this study, there were no treatment failures in any either cohort (antibiotics or no antibiotics).

\section{DISCUSSION}

Our systematic review found no evidence to support the routine use of antibiotics in addition to incision and drainage for the treatment of uncomplicated skin and soft tissue abscesses. The RR point estimates for treatment success in our three analyses range from 0.99 to 1.05 , although heterogeneity among studies and wide CIs in the RCT-only and MRSA-only analyses may limit the strength of our conclusions. Our results reinforce the findings of two previous, smaller reviews, while focusing particularly on CA-MRSA infections. ${ }^{25,26}$ Our findings support current IDSA guidelines, which recommend incision and drainage alone for 


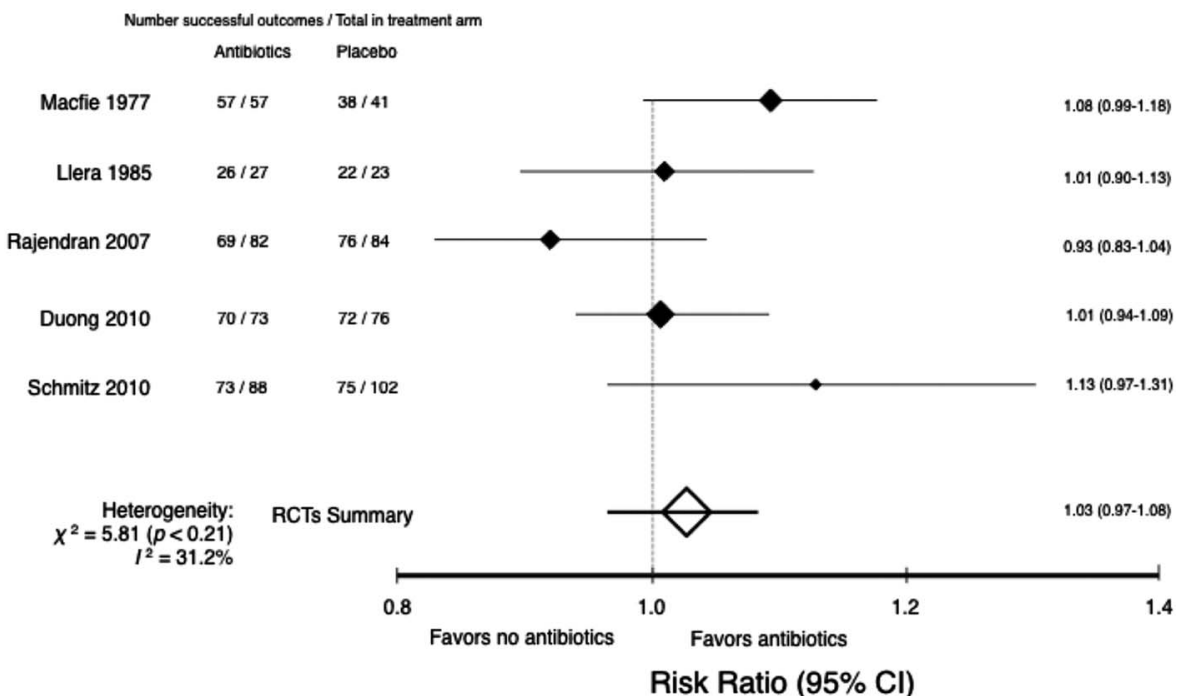

Figure 2. Randomized controlled trials forest plot. Note: RR $>1$ favors the use of antibiotics.

Table 5. Summary of studies included in each analysis with pooled results

\begin{tabular}{|c|c|c|c|c|c|}
\hline Analysis & $\begin{array}{l}\text { Number of } \\
\text { studies }\end{array}$ & $\begin{array}{l}\text { Studies included } \\
\text { (reference number) }\end{array}$ & $\begin{array}{l}\text { Random effects } \\
\text { RR }(95 \% \mathrm{Cl})\end{array}$ & $\begin{array}{c}\text { Fixed effects RR (shore- } \\
\text { adjusted } 95 \% \mathrm{Cl} \text { ) }\end{array}$ & $1^{2}$ \\
\hline RCTs only & 5 & $7,8,9,10,11$ & $1.03(0.97-1.08)$ & $1.03(0.97-1.08)$ & $31.2 \%$ \\
\hline MRSA-only & 4 & $13,14^{\dagger}, 17,15$ & $1.05(0.96-1.15)$ & $1.05(0.97-1.13)$ & $63.5 \%$ \\
\hline MRSA-era & 6 & $3,9,10,11,14,16$ & NA & $0.99(0.98-1.01)$ & $N A^{*}$ \\
\hline
\end{tabular}

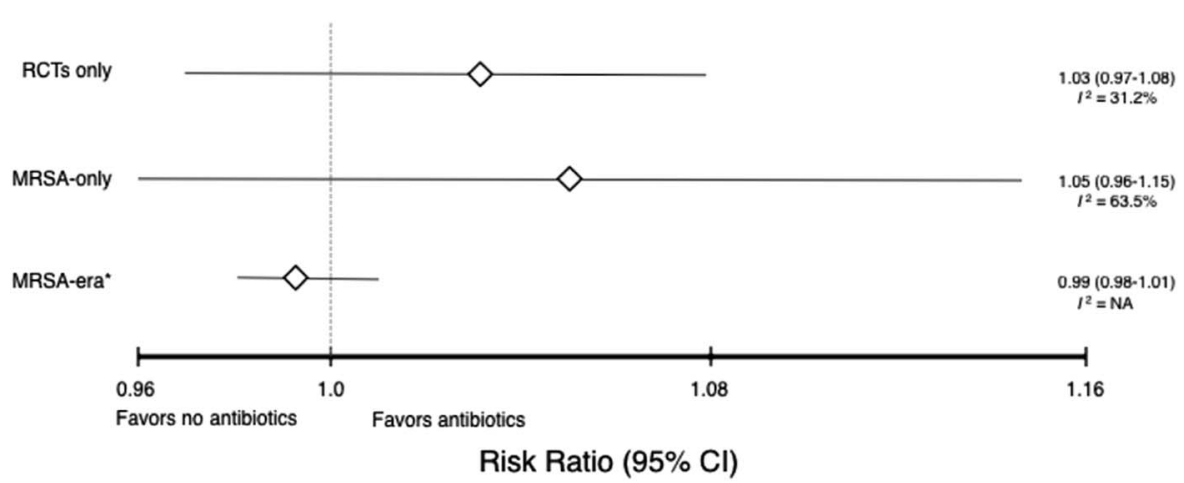

Figure 3. Summary of pooled analyses. This figure shows the pooled $\mathrm{RR}$ and $95 \% \mathrm{Cl}$ for the primary analysis and each secondary analysis. Note: RR $>1$ favors the use of antibiotics; RR $<1$ favors placebo, no antibiotics, or inappropriate antibiotics-described here as "favors no antibiotics."

*Fixed effects model results.

uncomplicated cutaneous abscesses, while acknowledging the need for more data. ${ }^{6}$

Our two secondary analyses attempt to address the question of whether antibiotics may be of particular benefit when CA-MRSA is a likely cause of the infection. This is an important question because CA-MRSA now causes a large proportion of community-associated SSTAs in the United States ${ }^{5}$ and a substantial, though more variable, proportion in Europe and Asia. ${ }^{28}$ Regardless of the exact clonal type, CA-MRSA is genotypically and likely phenotypically distinct from methicillin-sensitive S. aureus. The USA 300 strain, for 
example, although predominantly associated with furuncles and cutaneous abscesses, is also increasingly the cause of invasive disease in the United States. ${ }^{2}$ CAMRSA may represent a reason to treat even simple abscesses with antibiotics active against MRSA, or at least to lower the threshold for antibiotic treatment. In this light, it is significant that neither our MRSA-only or MRSA-era analyses found a statistically significant benefit from antibiotics. However, the MRSA-only analysis did find an RR point estimate of 1.05 , with an upper confidence limit of 1.15 , suggesting that the number needed to treat to prevent one treatment failure could be as low as seven and underscoring the need for more data.

Our study assesses the effect of adjunctive antibiotics on one important outcome; however, there are other potentially important outcomes not addressed, including abscess recurrence and antibiotic-related harms. With respect to recurrence, two trials found a significant reduction in new cutaneous abscesses (predominantly nearby "satellite" lesions) in the antibiotic group at 7 to 30 days, although this was not the primary outcome. ${ }^{10,11}$ Potential harms of antibiotics include rashes and severe allergic reactions; gastrointestinal side effects, including Clostridium difficile-associated diarrhea; yeast infections; and drug-drug interactions. Antibiotics cause 19\% of ED visits for drug-related complications, mostly allergic reactions, and sulfonamides and clindamycin are associated with the highest risk. $^{29}$ One trial included in our analysis reported adverse events in $20 \%$ of subjects treated with trimethoprim-sulfamethoxazole. ${ }^{10}$ More broadly, the development of resistance from increasing or inappropriate use of antibiotics has been identified as a major threat to public health and a reason for research to identify unnecessary antimicrobial therapies. ${ }^{30,31}$

Our study has a number of limitations inherent in meta-analysis, which we attempted to address. The most important of these is that the strength and validity of the overall conclusions depend on the number, size, and quality of included studies, and is limited by heterogeneity among studies. In order to capture all potentially relevant studies, we used an extensive search strategy, included multiple databases, and contacted authors directly to obtain additional data. The small number of included trials and total number of subjects may be insufficient to demonstrate a small statistically significant benefit (or harm) from antibiotics, which actually exists. We tried to strike an appropriate balance between including as many studies as possible and excluding those with quality issues. Some quality issues persisted in individual studies, including the enrolment of a nonconsecutive convenience sample (i.e., potential selection bias), attrition (i.e., incomplete outcome data bias), subjectivity of what constitutes a treatment failure (i.e., outcome assessment bias), and the use of telephone follow-up.

The problem of subjects lost to follow-up pervades many of the studies. The proportion lost to follow-up varies from $2 \%$ to $38 \%$. If all subjects lost to follow-up in the antibiotic arms were cured and all those in the nonantibiotic arms had a treatment failure, the analysis might have found a statistically significant benefit for antibiotics. It is more likely, however, that most patients lost to follow-up in both arms were cured (because patients with persistent symptoms or complications are more likely to return), thus minimizing the potential effect of patients lost to follow-up on overall results.

Heterogeneity among included studies was a significant problem. Although we attempted to account for measured heterogeneity by using both a random effects model and a fixed effects model with statistical correction in calculations of variance, unmeasured (clinical) heterogeneity was difficult to overcome. It is important to understand that, in SSTA studies, determinations regarding enrolment and exclusion criteria, as well as outcomes, are unavoidably subjective. These determinations likely varied by study setting, depending on whether the study population was pediatric or adult and whether providers were surgeons, internists, or emergency physicians. The type and severity of infections and the reported outcomes likely varied systematically among studies. For example, infections included in a study from a pediatric $\mathrm{ED}^{10}$ (and those excluded because they required admission) were likely different from those from an urban, public hospital surgical clinic serving injection drug users. ${ }^{9}$ Observational studies comparing inappropriate to appropriate antibiotics tended to enrol abscesses severe enough to be treated with antibiotics in normal practice, ${ }^{3,14}$ whereas other studies seemed to select relatively minor abscesses. ${ }^{11,12}$ Differences in antibiotic regimens used are another source of heterogeneity. Additional potential sources include differences in bacterial culture methods and sensitivity criteria used that were not uniformly reported. Although these many sources of clinical heterogeneity limit our pooled results and weaken our conclusion, we believe that our logically constructed 
secondary analyses, with careful attention to metaanalytic methods and detailed description of individual studies, should allow readers to draw independent conclusions.

The heterogeneity we observed among SSTA studies also reflects the fact that the disease itself is extremely heterogeneous. The term uncomplicated SSTA comprises a number of pathologic entities, each with a spectrum of severity. Examples include simple furuncles, cutaneous abscesses that extend down into the pannus of the buttock or thigh, cutaneous abscesses that have a substantial patch of surrounding cellulitis, and intramuscular abscesses due to injection drug use. Such a spectrum presents difficulties for both researchers and clinicians. For researchers, it makes it difficult to define and standardize inclusion criteria and determine treatment success or failure (i.e., whether further drainage is needed or whether persistent cellulitis is significant) among a range of infection types.

For practicing clinicians, it is difficult to apply uniform management to a fundamentally heterogeneous group of infections, particularly in the absence of evidence-based guidelines on how to gauge SSTA severity or identify an abscess as "complicated." For this reason, it is understandable that treatment decisions (i.e., no antibiotics, oral antibiotics, or parenteral antibiotics) and disposition (i.e., discharge, admission, or surgical consultation) have tended to err on the conservative side. In this light, our analysis of treatment trials and observational studies-which spans a range of study settings, infection types (including MRSA), and severity-showing that drainage alone, without adjunctive antibiotics, is sufficient treatment for uncomplicated SSTAs, should be reassuring to clinicians. Our results should further empower clinicians to say "no" to adjunctive antibiotics, with their associated expense and potential for harm.

Our results support a recommendation that treatment of uncomplicated SSTAs, even when MRSA is a likely etiology, should be with incision and drainage alone. Antibiotics should be reserved for special circumstances indicating a complicated infection, in accordance with IDSA guidelines. These circumstances include extensive disease, rapidly spreading associated cellulitis, associated phlebitis or lymphangitis, fever, comorbidities and immunosuppression, extremes of age, and lack of response to drainage alone. ${ }^{6}$ We recognize that, even in the absence of such circumstances, the term uncomplicated leaves clinicians with some latitude, particularly regarding surrounding cellulitis. Clinicians may choose to practice conservatively while awaiting more robust data.

The future research we look forward to seeing in this area includes large, multicentre trials comparing placebo to antibiotics active against CA-MRSA, with clearly defined enrolment and outcome criteria. Such trials are ongoing. ${ }^{32,33}$ Prospective observational studies and subgroup analyses from large trials are also needed to identify clinical features associated with adverse infection-related outcomes. Ultimately, physicians on the front-lines will need simple clinical decision rules to distinguish the small subgroup of patients with SSTAs who may benefit from adjunctive antibiotics from the vast majority who do not.

Competing interests: None declared.

\section{SUPPLEMENTARY MATERIAL}

To view supplementary material for this article, please visit http://dx.doi.org/10.1017/cem.2014.52

\section{REFERENCES}

1. Stevens DL, Bisno AL, Chambers HF, et al. Practice guidelines for the diagnosis and management of skin and soft-tissue infections. Clin Infect Dis 2005;41:1373-406.

2. Fridkin SK, Hageman JC, Morrison M, et al. Methicillinresistant Staphylococcus aureus disease in three communities. N Engl 7 Med 2005;352:1436-44.

3. Moran GJ, Krishnadasan A, Gorwitz RJ, et al. Methicillinresistant $S$. aureus infections among patients in the emergency department. N Engl 7 Med 2006;355:666-74.

4. Hersh AL, Chambers HF, Maselli JH, et al. National trends in ambulatory visits and antibiotic prescribing for skin and soft-tissue infections. Arch Intern Med 2008;168:1585-91.

5. Talan DA, Krishnadasan A, Gorwitz RJ, et al. Comparison of Staphylococcus aureus from skin and soft-tissue infections in US emergency department patients, 2004 and 2008. Clin Infect Dis 2011;53:144-9.

6. Liu C, Bayer A, Cosgrove SE, et al. Clinical Practice Guidelines by the Infectious Diseases Society of America for the Treatment of Methicillin-Resistant Staphylococcus Aureus Infections in Adults and Children. Clin Infect Dis 2011;52:1-38.

7. Macfie J, Harvey J. The treatment of acute superficial abscesses: a prospective trial. Br 7 Surg 1977;64:264-6.

8. Davis SL, Perri MB, Donabedian SM, et al. Epidemiology and outcomes of community-associated methicillin-resistant Staphylococcus aureus infection. 7 Clin Microbiol 2007;45: 1705-11.

9. Spellberg B, Boucher H, Bradley J, et al. To treat or not to treat: adjunctive antibiotics for uncomplicated abscesses. Ann Emerg Med 2011;57:183-5. 
10. Hankin A, Everett WW. Are antibiotics necessary after incision and drainage of a cutaneous abscess? Ann Emerg Med 2007;50:49-51.

11. Singer AJ, Thode HC Jr. Systemic antibiotics after incision and drainage of simple abscesses: a meta-analysis. Emerg Med 7 2014;31(7):576-8.

12. Hammond SP, Baden LR. Management of skin and soft-tissue infection-polling results. New Engl 7 Med 2008; 359:e20.

13. Pallin DJ, Egan DJ, Pelletier AJ, et al. Increased US emergency department visits for skin and soft tissue infections, and changes in antibiotic choices during the emergence of community-acquired methicillin-resistant Staphylococcus aureus. Ann Emerg Med 2008;51:291-8.

14. Moher D, Liberati A, Tetzlaff J, et al. Preferred reporting items for systematic reviews and meta-analyses: the PRISMA statement. PLoS Med 2009;6:e1000097.

15. Stroup DF, Berlin JA, Morton SC, et al. Meta-analysis of observational studies in epidemiology: a proposal for reporting. 7AMA 2000;283:2008-12.

16. Higgins J, Green S., eds. Cochrane Handbook for Systematic Reviews of Interventions Version 5.01. London: The Cochrane Collaboration; 2008.

17. Wells GA, Shea B, O'Connell D, et al. The NewcastleOttawa Scale (NOS) for assessing the quality of nonrandomised studies in meta-analyses. Available at: http:// www.ohri.ca/programs/clinical_epidemiology/oxford.asp (accessed August 18, 2013).

18. Herold BC, Immergluck LC, Maranan MC, et al. Community-acquired methicillin-resistant Staphylococcus auresus in children with no identified predisposing risk. 7AMA 1998;279:593-8.

19. Shrier I, Boivin JF, Steele RJ, et al. Should meta-analyses of interventions include observational studies in addition to randomized controlled trials? A critical examination of underlying principles. Am 7 Epidemiol 2007;166:1203-9.

20. Golder S, Loke YK, Bland M. Meta-analyses of adverse effects data derived from randomised controlled trials as compared to observational studies: methodological overview. PLoS Med 2011;8:e1001026.

21. Higgins JP, Thompson SG, Deeks JJ, et al. Measuring inconsistency in meta-analyses. BMJ 2003;327:557-60.
22. Hatala R, Keitz S, Wyer P, et al. Tips for learners of evidence-based medicine: 4. Assessing heterogeneity of primary studies in systematic reviews and whether to combine their results. CMA7 2005;172:661-5.

23. Greenland S. Quantitative methods in the review of epidemiologic literature. Epidemiol Rev 1987;9:1-30.

24. Shore RE, Gardner MJ, Pannett B. Ethylene oxide: an assessment of the epidemiological evidence on carcinogenicity. Br 7 Ind Med 1993;50:971-97.

25. DerSimonian R, Laird N. Meta-analysis in clinical trials. Control Clin Trials 1986;7:177-88.

26. Egger M, Davey Smith G, Schneider M, et al. Bias in metaanalysis detected by a simple, graphical test. BMF 1997; 315:629-34.

27. Begg CB, Mazumdar M. Operating characteristics of a rank correlation test for publication bias. Biometrics 1994; 50:1088-101.

28. Chua K, Laurent F, Coombs G, et al. Antimicrobial resistance: Not community-associated methicillin-resistant Staphylococcus aureus (CA-MRSA)! A clinician's guide to community MRSA its evolving antimicrobial resistance and implications for therapy. Clin Infect Dis 2011;52:99-114.

29. Shehab N, Patel PR, Srinivasan A, et al. Emergency department visits for antibiotic-associated adverse events. Clin Infect Dis 2008;47:735-43.

30. Schwartz B, Bell DM, Hughes JM. Preventing the emergency of antimicrobial resistance. A call for action by clinicians, public health officials, and patients. $7 A M A$ 1997; 278:944-5.

31. Wise $\mathrm{R}$, Hart $\mathrm{T}$, Cars $\mathrm{O}$, et al. Antimicrobial resistance. Is a major threat to public health. BMF 1998;317:609-10.

32. National Institute of Allergy and Infectious Diseases (NIAID). Strategies using off-patent antibiotics for methicillin resistant S. aureus "STOP MRSA." Available at: http:// clinicaltrials.gov/ct2/show/NCT00729937 NLM Identifier: NCT00729937 (accessed December 12, 2012).

33. National Institute of Allergy and Infectious Diseases (NIAID). Uncomplicated skin and soft tissue infections caused by community-associated methicillin-resistant Staphylococcus aureus. Available at: http://clinicaltrials.gov/ct2/show/ NCT00730028 NLM Identifier: NCT00730028 (accessed December 12, 2012). 